\title{
Sobre algunas sentencias contradictorias del Tribunal Superior de Xusticia de Galicia en materia de cooperación intraprovincial
}

\author{
$\mathbf{M}^{\mathbf{a}}$ Teresa Carballeira Rivera \\ Profesora de Derecho administrativo \\ Universidad de Santiago de Compostela
}

A lo largo de los años 1990 y 1991, la Sección II del Tribunal Superior de Xusticia de Galicia (en adelante TSXG) ha tenido ocasión de pronunciarse sucesivamente sobre la adecuación o no a Derecho de los distintos Planes Provinciales de Cooperación a las Obras y Servicios Municipales (en adelante PPOS) elaborado por la Diputación de Lugo. Las dos primeras Sentencias dictadas el 27 de Noviembre de 1990 y el 5 de Diciembre de 1990, abordan la cuestión litigiosa desde una perspectiva netamente divergente de las dos posteriores, las Sentencias de 12 de Octubre de 1991 y de 8 de Noviembre de 1991. Remitimos, pues, este estudio al análisis y contraposición de las argumentaciones jurisprudenciales que se reflejan en estos dos grupos de Sentencias.

\section{I}

Primeramente, es necesario hacer algunas puntualizaciones respecto de los antecedentes de hecho comunes a todas las Sentencias. La Diputación de Lugo aprobó inicialmente el PPOS, dando traslado posteriormente de dicho Plan a todos los Ayuntamientos de la provincia, la Comisión provincial de Colaboración con las Corporaciones Locales y el Ministerio para las Administraciones Públicas, al tiempo que abría un plazo de información pública mediante edicto publicado en el B.O.P. La Comisión de Colaboración con las Corporaciones Locales emitió informe desfavorable, basándose en la desnaturalización de los cometidos y contenidos del Plan, dado que en él se incluían obras no solicitadas previamente por los municipios receptores del Plan Provincial. Según este informe, «el Plan Provincial de Obras y Servicios municipales es una forma de colaboración con los municipios, por lo cual es preciso que para la inclusión de cada obra sea necesaria la aprobación previa del municipio». Pese a todo, la Diputación aprobó el Plan sin te- 
ner en consideración dicho informe, por lo que el mismo fue impugnado en su día por el Abogado del Estado, en representación y defensa de la Administración estatal. Este presupuesto de hecho se repite en las cuatro sentencias citadas, si bien los Planes provinciales responden a años diferentes, abarcando el período de 1987 a 1990, y los fallos del TSXG difieren, siendo en las dos primeras sentencias desestimatorios del recurso contencioso-administrativo y en las dos últimas estimatorio. Todas estas sentencias contienen voto particular de uno de los magistrados, en cuya fundamentación se recoge una opinión radicalmente opuesta a la sostenida por la mayoría en cada caso.

Es preciso igualmente hacer notar que el soporte normativo utilizado por el Tribunal para dictar estas Sentencias se ciñe, básicamente, a la Constitución española, la LBRL y el Real Decreto 1673/1981, de 3 de julio, sobre Régimen de Planes Provinciales de obras y servicios, hoy en día derogado y sustituido por el Real Decreto 665/1990, de 25 de Mayo, por el que se regula la cooperación económica del Estado a las inversiones de las Entidades Locales.

\section{II}

Efectuaremos el análisis de los pronunciamientos del TSXG, de acuerdo con una metodología concreta que tratará de contraponer, en cada momento, los distintos planteamientos y la filosofía jurídica de fondo que inspira al Tribunal para llegar a conclusiones tan dispares respecto de una misma cuestión, esto es, decidir si la inclusión de obras en los PPOS exigen, siempre y en todo caso, el previo acuerdo de los Ayuntamientos afectados.

Parte el Tribunal de la definición de las relaciones entre provincia y municipios en materia de cooperación intermunicipal tomando como base la que aporta el art. 36 LBRL en conexión con el art. 31.2 LBRL. Según esto, «el Plan Provincial de Cooperación atiende precisamente, y entre otras finalidades, a la coordinación de los servicios municipales entre sí para la garantía de la prestación integral y adecuada a que se refiere el apartado a) del número 2 del artículo 31, así como la asistencia y la cooperación jurídica, económica y técnica a los Municipios, especialmente a los de menor capacidad económica y de gestión».

Sobre la base de estos dictados legislativos el Tribunal procede, acto seguido, a plantearse como clave de bóveda de toda la cuestión litigiosa la de averiguar cuál ha de ser el alcance de las técnicas instrumentales establecidas por el Ordenamiento para la elaboración y tratamiento jurídico del Plan. En otros términos, el problema principal no es otro que 
JURISPRUDENCIA

el de concretar el significado de conceptos jurídicos como coordinación $y$ cooperación. A estos efectos, y tomando como punto de partida el hecho de que en la coordinación y cooperación reside la verdadera naturaleza de las relaciones competenciales entre Diputación y Ayuntamientos, el Tribunal comienza a elaborar un minucioso análisis de tales mecanismos de relación interadministrativa, que traerá como consecuencia la disparidad doctrinal que preside los fallos de estas cuatro Sentencias.

Así, en las STSXG de 27 de noviembre y 5 de diciembre de 1990, el Tribunal aporta una definición de la cooperación interadministrativa en los siguientes términos:

«Entendiendo la cooperación como la conjunta actuación dentro de las respectivas competencias para la consecución de un fin determinado [...], un primer límite se establece para la actuación de los Entes provinciales en cuanto, en el Plan objeto de litigio, habrán de quedar excluidas aquellas obras y servicios de exclusivo interés provincial o supramunicipal, residenciándose en éste exclusivamente las de interés municipal». (Fundamento cuarto).

Consecuentemente, y siempre que estemos ante un título cooperante, no cabe la inclusión de inversiones municipales en los PPOS no consentidas por los municipios receptores:

"En sede de cooperación, no puede la provincia decretar la prestación de servicios municipales en contra de la decisión municipal, como se sigue, por lo demás, del carácter voluntarista que se otorga a la cooperación en el artículo 57 LBRL, debiendo desistir de su propósito en la aprobación definitiva la Corporación provincial que, tras incluir una obra o servicio en el Plan, en vía de cooperación, advierte la oposicion del Ayuntamiento respectivo". (Fundamento cuarto).

Llegados a este punto, habría de asentir que aquellas obras o servicios que gocen de carácter supramunicipal o, si se quiere, provincial, no pueden incluirse en los PPOS, máxime cuando esas inversiones no han sido sugeridas ni consentidas por los Municipios beneficiarios de los Planes de cooperación provincial. No obstante, el TSXG va más allá en sus deducciones, e intenta dar un giro diametral a la interpretación jurídica hecha hasta ahora a través de la aplicación del elemento coordinante. A este respecto, conviene señalar que, para el TSXG, la articulación de la "competencia coordinante" de las Diputaciones provinciales, desvirtúa el título cooperante, dando un sentido netamente diverso. En este sentido, señalan las dos Sentencias citadas lo siguiente: 
«La Diputación (artículos 31.2,a) y 36.1,a) LBRL) no sólo tiene competencia, sino que viene obligada por Ley a asegurar y garantizar la íntegra y adecuada prestación de los servicios municipales, señaladamente los mínimos consignados en el artículo 26.1 LBRL. Tal mandato legal, cuando no es factible a través de la cooperación, puede hacerse efectivo mediante las facultades provinciales de coordinación, en cuanto ordenación común de las actividades atenientes a diversos sujetos, facultades contempladas en el artículo 36.1,a) LBRL cuya instrumentación (artículo 36.2) se efectúa mediante los Planes provinciales de cooperación». (Ibídem).

De ahí que:

«Es en este supuesto de insuficiencia o inconveniente prestación de los servicios municipales mínimos, sintéticamente coincidentes con los llamados a incluirse en los Planes [...] cuando el ámbito de decisión es de la provincia y puede ejecutarse sin la aceptación del Municipio afectado". (Ibídem).

Añade seguidamente el Tribunal una cautela adicional para el caso de que esa "insuficiencia o inconveniencia de la prestación" faculte a la Diputación a incluir obras y servicios no aceptados o aprobados por los Municipios, y es la de la renovación del acto aprobatorio provincial:

"Ciertamente ello comporta una exigencia de específica motivación por parte de la Corporación provincial al aprobar definitivamente el respectivo Plan, en cuanto afecta a la voluntad y actuación de los Municipios afectados, provocando su ausencia la anulabilidad del acto en los términos del artículo 48.2 de la Ley de Procedimiento Administrativo». (Fundamento quinto).

\section{III}

Pues bien, toda esta doctrina establecida por el TSXG a lo largo de las citadas sentencias de 1990, va a ser velada por dos Sentencias dictadas con posterioridad, concretamente, la STSXG de 12 de octubre de 1991 y la STSXG de 8 de noviembre de 1991, en las que, si bien, el punto de partida es coincidente, no así su desarrollo y colusiones. Pero vayamos por partes. Según el Tribunal, la articulación de los instrumentos de cooperación y coordinación que regula la LBRL en favor de las Diputaciones Provinciales conlleva, en cualquier caso, una premisa básica:

"La de que ninguno de los Entes sometidos a coordinación o cooperación pierda un ápice de sus competencias propias (señaladas 
JURISPRUDENCLA

previamente en normas sustantivas al efecto) por el hecho de entrar en uno de esos instrumentos de carácter simplemente operativo y armonizador, nunca definidor de límites competenciales». (Fundamento tercero).

En estrecha relación con esta doctrina que defiende la inalterabilidad de los títulos competenciales, se halla una consecuencia que conduce ineluctablemente a un principio fundamental para delimitar los términos en los que debe moverse el PPOS:

"Que las obras han de ser propuestas por el Ayuntamiento regidor del territorio en que vayan a realizarse, y que ningún otro organismo puede decidir qué obras de las de esa competencia municipal son las convenientes para ese concreto municipio; otra conclusión supondría la intromisión de otro organismo en facultades de asunción municipal, resultando inaceptable en un Estado compuesto como el español». (Fundamento segundo).

Así pues, ni la coordinación ni la cooperación como competencia que es de la Diputación provincial, según lo determina la LBRL, pueden suponer, bajo ningún pretexto, la imposición por esta Corporación de decisiones contrarias a la voluntad municipal. Ello no obsta, como dicen acto seguido la Sentencias mencionadas, para que la Diputación ostente una serie de facultades respecto de los PPOS en virtud, justamente de esas competencias de coordinación y cooperación. Facultades que, únicamente, pueden traducirse en la posibilidad de imponer un determinado procedimiento de elaboración del Plan y decidir las obras a realizar de acuerdo con los criterios objetivos que aquélla establezca. En palabras del propio Tribunal:

«La potestad coordinadora y cooperadora de la Diputación ha de suponer lógicamente la posibilidad de establecer un determinado procedimiento colectivo para la elaboración del Plan y también ha de comportar una posible y aconsejable determinación de los criterios que le parecen más adecuados a una equilibrada satisfacción de las necesidades colectivas, $y$, como consecuencia de ello, y estándole expresamente atribuida la competencia de aprobación del Plan, (la Diputación) dentro de las obras propuestas por los únicos Organismos competentes para decidir su conveniencia municipal (los Ayuntamientos), decidir las que por estar acomodadas al procedimiento y a los objetivos antes señalados merecieren ser realizadas y las que no proceda hacerlo; lo que no puede es subrogarse en las competencias municipales para decidir qué otra cosa no prevista por el Organismo municipal le habría convenido decidir a éste». (Fundamento tercero). 
En síntesis, pues, desde la perspectiva de la actual doctrina del TSXG no puede hablarse ni de coordinación ni de cooperación como títulos habilitantes que permitan a la Diputación introducir en el PPOS determinadas inversiones no solicitadas por los Municipios destinatarios. Este razonamiento jurisprudencial es, a nuestro parecer, mucho más acertado y acorde con la idea que hoy en día asume nuestro Ordenamiento jurídico de la autonomía local. La STC 27/1987, de 27 de febrero, fj. $3^{\circ}$, ofrece una definición elaborada de la autonomía local, entendiendo por tal «el derecho de la comunidad local a participar, a través de sus órganos propios, en el gobierno y administración de cuantos asuntos le atañen". O mutatis mutandi, no existe autonomía si el ente territorial no goza de potestades públicas para perseguir la finalidad e intereses propios de su respectiva colectividad, según su propia dirección político-administrativa. Idea, perfilada, a su vez con gran maestría por el art. 7 LBRL cuando señala que «las competencias propias locales se ejercen en régimen de autonomía y bajo la propia responsabilidad». Significa esto, entre otras cosas, que va a existir un ámbito de libertad e independencia para el ente, en el cual le está permitido actuar en el ejercicio de sus competencias propias, sin determinaciones exteriores a su propia organización que limiten su capacidad de darse una dirección política y administrativa específica. Y, además, la alusión a una actuación responsable, conlleva la asunción de decisiones propias, manifestadas en actos expresivos de la tendencia o elección política de la Corporación gobernante, responsable únicamente ante su electorado, sin que en ese proceso de toma de responsabilidades quepan injerencias mediatizadoras que sometan al ente a una subordinación ilegítima.

Bien es cierto, no obstante, que la delimitación del principio de autonomía debe cohonestarse con aquellos otros instrumentos de relación interadministrativa, tales como la coordinación y la cooperación. Sin embargo, ya estemos ante un poder que presupone una cierta "voluntariedad" de las partes en relación (cooperación), ya ante un "cierto poder de dirección consecuencia de la posición de superioridad en que se encuentra el que coordina respecto del coordinado" (coordinación) (STC 214/1989, de 21 de Diciembre, fj. 20), resulta imposible extender ilimitadamente la proyección de los efectos de estos mecanismos hasta menoscabar la autonomía local. En otros términos, la traducción positiva de estos mecanismos, se halla flanqueada por dos límites que suponen, por abajo, la preservación de un «ámbito de decisión autónoma para el coordinado"; y, por arriba, una diferenciación de tales técnicas de las típicas de control. Consiguientemente, y haciéndonos eco de la idea del Tribunal, los medios y técnicas de coordinación deben respetar un 
margen de libre decisión o de discrecionalidad en favor de las Administraciones sujetas a la misma, sin la cual no puede existir verdadera autonomía" (STC 27/1987, de 27 de febrero, fj. $4^{\circ}$ ).

Partiendo de esta óptica jurisprudencial y reconduciendo el significado de estos instrumentos al ámbito de las relaciones entre Municipios y Diputaciones, hay que convenir con los últimos pronunciamientos del TSXG y afirmar que ni el fin cooperante de los PPOS (asegurar y garantizar la íntegra y adecuada prestación de los servicios municipales y señaladamente los mínimos preceptuados por el art. 26.1 LBRL) ni el coordinador (garantizar que esa prestación a que hace referencia el art. 31.2.a) LBRL sea efectivamente factible y adecuada) pueden promover la alteración de los títulos competenciales. En consecuencia, no cabe apelar a estos instrumentos de relación para incluir en el PPOS obras y servicios no consentidos por los municipios, ya que ello sería tanto como legitimar a un ente para asumir las correspondientes facultades y actuar, política y administrativamente, en sustitución de otro y sobre un ámbito competencial ajeno. Ello no quiere decir que esa coordinación formal que ostenta la Diputación provincial en el ejercicio de una actividad cooperante planificada, no pueda materializarse de una forma efectiva. Antes bien, la articulación de los instrumentos coordinadores por parte de los órganos provinciales en beneficio de la homogeneidad técnica y la armonía de resultados se ha de manifestar en unas capacidades concretas en favor de la Diputaciones. Así, la Diputación ostentará plena capacidad para establecer los criterios -de acuerdo con una bases objetivas y sin perjuicio de la coordinación ejercida por la Administración autonómica- a los que sujetar su actividad cooperante y, el poder decidir y seleccionar, dentro de las obras municipales propuestas, aquéllas que, por estar acomodadas al procedimiento y objetivos señalados por la Corporación provincial, merezcan ser realizadas desestimando, consiguientemente, las que considere inadecuadas, bien por revestir un carácter no prioritario, bien por cualesquiera otras causas que hagan inadecuada su ejecución o prestación desde la perspectiva intermunicipal.

Por lo demás, la necesidad de participación previa de los Municipios en la formación del PPOS ha sido totalmente asumida como requisito necesario por la legislación vigente, (art. 36.2.a) y Real Decreto 665/1990, de 25 de Mayo) y en este sentido, el Municipio, a través de sus Planes Anuales municipales, debe transmitir a la Diputación las propuestas, datos y deficiencias infraestructurales del área municipal. Finalmente, añadir también que la Diputación cuenta con otros instrumentos jurídicos, Planes de Acción especial y Planes Sectoriales- para la realización de obras de carácter supramunicipal- hecho que, indirectamente, excluye este tipo de obra de aquellos planes netamente de ámbito cooperativo municipal. 
